\title{
A NARRATIVA DO XADREZ: um projeto de jogo imersivo narrativamente
}

\author{
Vinícius Hengles Monteiro \\ Centro Universitário Belas Artes de São Paulo \\ vmonteiro685@gmail.com \\ Guilherme Ranoya \\ Centro Universitário Belas Artes de São Paulo \\ ranoya@gmail.com
}

\begin{abstract}
Resumo: Este artigo discute o descolamento da narrativa do xadrez desde algumas histórias que cercam sua origem até se tornar o que conhecemos hoje, um jogo marcado por um conjunto de regras organizado por alguns nomes de uma sociedade medieval clássica. A partir dessas reflexões, propõe um projeto de uma variação do xadrez com base nos conceitos em oposição de imersão estratégica e imersão narrativa, buscando identificar no estilo de jogo Role Playing Game (RPG) as ferramentas necessárias para estimular a narrativa participativa. O projeto trata em especial das mudanças quanto à forma do tabuleiro, da inserção de um novo personagem, o herói, e das cartas de evento.
\end{abstract}

Palavras-chave: Design, Jogo, Xadrez, RPG

\begin{abstract}
This article is about chess, but mainly the way that it loses its narrative aesthetics over time. Nowadays, the game seems to be just an arrangement of rigid rules organized by some names of a classical medieval society (king, queen, bishops and on). These initial thoughts lead it to project a new version of chess based on opposite concepts such as strategic immersion and narrative immersion. It tries to identify the essential tools in Role Playing Game (RPG) to stimulate participative narratives. The project of the game deals with board shape changes, with a new character added as a hero and the event cards.
\end{abstract}

Keywords: Design, Game, Chess, RPG

\section{INTRODUÇÃO}

O xadrez representa um campo de batalha. Quando os dois jogadores se enfrentam, cada um move a seu tempo um integrante de um exército formado por peões, cavaleiros, bispos, torres, rainha e rei, com um único objetivo: capturar o rei inimigo. Contudo, mesmo que essa premissa permita construir uma narrativa, durante o jogo, não é o que acontece - nem antes e nem depois. 
Ainda que a origem do jogo esteja cercada por narrativas bélicas, podemos dizer que as modificações que sofreu através do tempo destituíram a importância dessas histórias, restando apenas um conjunto de regras que podem ser usadas até mesmo sem qualquer suporte material.

Partindo desse pressuposto, que a seguir será melhor explicado, surgiu o interesse em discutir as soluções viáveis em jogabilidade a fim de propor um projeto de uma versão do xadrez que estimule a imersão narrativa, que tenha uma estética narrativa.

Apesar de usar o termo estética, não nos referimos aos aspectos visuais, mas ao que, de acordo com a abordagem Mechanics, Dynamics, and Aesthetics (MDA), cria a experiência do jogador. Os autores Robin Hunicke, Marc LeBlanc e Robert Zubek (2004) explicam que a abordagem MDA serve para fazer uma ponte entre design de jogos, desenvolvimento, crítica e pesquisa.

O design de jogos é, portanto, uma etapa anterior ao desenvolvimento, que envolve "um sistema de ideias que definem o que são jogos e como eles funcionam" (SALEN; ZIMMERMAN, 2004, p. 5). Assim, ao longo deste artigo observamos o xadrez pela abordagem MDA, para entender inicialmente sua estética e só então propor uma nova narrativa. Fazendo isso, descrevemos nossas escolhas sobre os recursos emprestados do Role Playing Game (RPG), tipo de jogo cuja base está na criação participativa de histórias, para definir os caminhos do que pode ser feito num segundo momento.

Com a intenção de compreender o processo de desenvolvimento do projeto, que se deu à luz de autores como Janet H. Murray (2003), Ernest Adams (2004) e Joris Dormans (2006), entre outros, é necessário, a princípio, revisitar as narrativas que envolvem a origem do jogo.

\section{AS ORIGENS NARRATIVAS DO XADREZ}

Consideramos o Chaturanga a origem do jogo. Este, de acordo com Duncan Forbes (1860), foi criado pela esposa de Ravana, rei de Lanka, para diverti-lo com a imagem da guerra. Formado por quatro exércitos, com peças que representavam infantaria, navios, cavalos e elefantes, era um jogo de aposta e jogava-se com dados.

O mesmo autor cita uma segunda narrativa, em que Yudhishthira apostou e perdeu tudo e até mesmo sua mulher para seu inimigo, Shakuni. O pai deste, Dhritarashtra, maravilhado com a esposa do perdedor, concedeu a ela tudo o que pediu, ou seja, a restauração dos bens de seu marido. Entretanto, Yudhishthira encontrou-se com Shakuni para jogar uma vez mais e perdeu tudo novamente.

Uma terceira narrativa conta sobre Kaid, um rei apaixonado pela guerra, vitorioso em todas as suas batalhas a ponto de não ter mais com quem guerrear. Chamou Sassa, seu ministro, e expôs seu problema: pensava em guerra de dia e de noite e não tinha paz. Sassa lembrou-se de um jogo criado pelos gregos que representava a imagem perfeita de uma guerra entre dois reinos. Buscou-o, estudou-o até descobrir como as peças se moviam, e, por fim, decidiu que era muito complexo. Simplificou-o, reduzindo o número de peças de 56 para 32, padronizando a movimentação destas e diminuindo o número de espaços do tabuleiro para 64 . Somente depois disso apresentou o jogo ao rei Kaid, que encontrou a paz almejada (FORBES, 1860). 
Em uma variante dessa narrativa, Sassa, primeiro-ministro, apresentou ao príncipe inexperiente - que, após o falecimento de seu pai, deveria aprender sobre a guerra para defender seu reino - o jogo que era a imagem da guerra:

Aqui você tem a imagem exata de uma guerra, que é conduzida por princípios similares àqueles que regram este maravilhoso jogo. 0 mesmo cuidado no ataque, e a frieza na defesa, que você deve exercitar aqui, você terá ocasião para colocar em prática no campo de batalha. (FORBES, 1860, p. 67)

Quando o príncipe dominou os princípios do jogo, partiu para a guerra e retornou triunfante.

Uma última variante da terceira narrativa conta da disputa de dois irmãos pelo reino após o falecimento do pai. A mãe deixou que o exército e o povo decidissem a qual dos dois irmãos iria o mérito do reino, o que resultou em uma guerra civil, e os dois irmãos decidiram se enfrentar no campo de batalha. O mais velho foi vitorioso, e quando seus soldados cercaram seu irmão montado num elefante, descobriram-no morto de desgosto e humilhação, sem nenhum dano físico. A rainha ficou inconsolável e culpou o irmão mais velho pela morte do outro, ainda que ele tentasse, em vão, explicar sua inocência. Foi então que Sassa trouxe à rainha o xadrez, para entretê-la e ao mesmo tempo explicar como o irmão mais novo, cercado pelo exército inimigo, faleceu de desgosto. Ao passo que a rainha jogava com Sassa, convenceu-se de que seu filho mais velho era inocente (FORBES, 1860).

Mesmo que o tempo tenha modificado o nome, algumas peças e o tabuleiro, a essência do xadrez, ou seja, sua imagem e semelhança à guerra, continuou a mesma. Evidentemente isto é um aspecto estético, e, para compreender melhor a dissolução de sua importância, convém observar o xadrez de acordo com a abordagem MDA (Mechanics, Dynamics, and Aesthetics), proposta pelos autores Robin Hunicke, Marc LeBlanc e Robert Zubek (2004).

\subsection{O xadrez de acordo com a abordagem MDA}

Entende-se por Estética (Aesthetics) a resposta emocional desejada evocada no jogador. Por Dinâmica (Dynamics) entende-se a maneira com que se cria a experiência estética. Mecânica (Mechanics), por fim, são as regras do jogo.

Podemos perceber que o xadrez manteve a estética narrativa, e por isso o reconhecemos como tal. Quando a rainha cria o jogo para entreter seu marido, a mecânica era diferente, e a dinâmica, por sua vez, também, mas a estética era a mesma. A intenção era recriar a cena, o drama da guerra.

Nas demais histórias a situação é semelhante. Quando Yudhishthira apostou seu reino, fortuna e família com Shakuni, eles também estavam recriando o drama da guerra, sem que, de fato, precisassem fazê-la. Nas histórias de Sassa, ele resolve os problemas apresentando aos reis e rainha o xadrez, e também há a representação da guerra, a recriação da cena para entreter o rei entediado, para treinar o jovem príncipe e para inocentar o filho mais velho da rainha.

Contudo, chega o momento em que a estética narrativa perde sua força. Forbes (1860) diz que há um manuscrito persa intitulado "Munjih fi'ilm al Shatriuij" [Monitor de jogadores de xadrez] com várias instruções sobre o jogo - particularmente sobre como jogá-lo sem ver o tabuleiro. Semelhante a este, outro manuscrito persa 
traz a história da jornada do autor por várias terras árabes, jogando contra grandes mestres. O jogador, discípulo de Deus, agradece a ele por todas as suas vitórias, principalmente aquelas em que jogou usando o tabuleiro, enquanto, ao mesmo tempo, vencia outros quatro oponentes sem suporte material.

Possivelmente, o momento mais expressivo do descolamento da narrativa é quando o autor nos conta que o profeta Maomé alude ao jogo como um pecado, quando afirma que "imagens" devem ser evitadas. O termo refere-se à forma das peças, pois, como foram criadas na Índia, seriam representações de ídolos - e, portanto, jogar o jogo seria idolatria. Os muçulmanos que queriam continuar jogando criaram peças cuja forma não representava nenhuma criatura vivente.

Neste ponto o xadrez atinge o máximo de sua abstração. Não era mais a recriação de drama algum, era apenas duas pessoas envolvidas por uma série de possibilidades estratégicas a serem executas num tabuleiro físico ou imaginário. Mecânica pura com uma dinâmica estratégica e matemática.

No ocidente, o jogo continuou com as representações - não que fosse o bastante para sustentar a narrativa. Conforme se espalhou por toda a Europa, a forma das peças variava muito de região para região, de acordo com um artigo digital da revista Smithsonian escrito por Jimmy Stramp (2013). Quando clubes de xadrez começaram a ser formalizados, foi preciso criar um padrão visual, e, a partir de 1849, o jogo tornou-se o que é hoje, com as peças conhecidas por The Staunton.

Há, portanto, uma narrativa no xadrez atual? Eric Zimmerman (2004) afirma existir uma narrativa quando observamos o xadrez de acordo com o esquema proposto por J. Hillis Miller (apud Zimmerman, 2004), em que narrativa é algo composto por eventos, ou seja, um estado inicial, uma mudança e o resultado desta. Além disso, a narrativa também é a personificação desses eventos num meio, e, por último, é constituída por essas representações de forma padrão e repetida.

O autor detalha que o xadrez tem seu estado inicial quando as peças estão organizadas, uma mudança quando as peças são movidas e, por fim, o resultado do jogo, assim como é a representação estilizada de uma guerra, com uma série completa de personagens atuantes numa estrutura padronizada de turnos sobre um tabuleiro concebido a partir de uma grade.

Ainda assim, no trecho da descrição de uma partida de xadrez não há indicação dessa representação. A descrição dos cinquenta movimentos de Kasparov em sua vitória no trigésimo quarto campeonato mundial ilustra bem este argumento:

[...] Kg1 Qe616. Qd3 Qc4 17. Qxc4 Nxc4 18. Bf2 cxd4 19. cxd4 e5 20. d5 Bh6 21. h4 Bd2 22. Rd1 Ba523. Rc1 b5 24. Rc2 Nd6 25. Ng3 Nc4 26. Nf1 Nd6 27. Ng3 Nc4 28. g5 Kf7 29. Nf1 Nd630. Ng3 Nc4 31. Kf1 Ke7 32. Bc5 Kf7 33. Rf2 Kg7 34. Rf6 Bb6 35. Rc6 Na5 36. Bxb6Nxc6 37. Bc7 Rf8 38. Ke2 Rf7 39. Bd6 Rd7 40. [...](NIFTY 50!..., 2013)

Ainda que qualquer pessoa que não seja familiarizada com o jogo consiga identificar o que cada peça simboliza, ela pode não compreender nenhum dos movimentos descritos acima. Isso prova que a narrativa pode até existir, mas definitivamente não é ela que imerge o jogador no círculo mágico. 


\subsection{Imersão estratégica versus imersão narrativa}

Imersão, segundo Janet H. Murray (2003), é estar submerso na água; metaforicamente falando, é estar com todo nosso sistema sensorial inundado, cercado por uma realidade diferente que domina nossa atenção.

Jogar xadrez significa que se está alheio, concentrado na dinâmica do jogo, logo, imerso numa série de estratégias montadas a partir da mecânica. Assim, podemos classificar sua imersão como imersão estratégica.

Essa classificação, segundo Ernest Adams, refere-se ao envolvimento cerebral do jogador com o jogo, no qual toda sua atenção está voltada para a observação, o cálculo e a dedução. "A mais alta, mais abstrata forma de imersão estratégica é experienciada por mestres de xadrez, que se concentram em encontrar o movimento correto num vasto número de possibilidades" (ADAMS, 2004).

Para o autor, os jogadores imersos estrategicamente não se importam com a narrativa do jogo. Numa partida de xadrez, por exemplo, os jogadores passam o tempo todo em silêncio, e, como já sabemos, poderia ser substituída a forma de todas as peças do jogo por blocos de cores ou tamanhos diferentes que ainda seria possível permanecer mergulhado em sua dinâmica.

Em oposição a esse tipo de imersão, Adams (2004) define a imersão narrativa. $\mathrm{O}$ jogador presta maior atenção aos personagens e ao que lhes acontece. Preocupa-se com eles, semelhante ao que acontece na leitura de livros ou assistindo a filmes. Este tipo de imersão permite elementos estratégicos em sua dinâmica, pois mesmo assim o interesse do jogador estará voltado para a conclusão da narrativa. Dessa maneira, faz sentido imaginar o xadrez em sua origem com uma estética narrativa, por mais que tivesse elementos estratégicos. Era jogador por ser a imagem da guerra, se tivesse outra estética, os reis e rainha não teriam se interessado.

Dois tipos de imersão diferentes que atraem dois públicos diferentes. Àqueles que pouco se importam com o que as peças representam, o xadrez já é sedutor. Nossa tarefa, neste segundo momento, é tornar o jogo sedutor àqueles que se perguntam, por exemplo, por que o jogo termina quando o rei é capturado se a rainha poderia reinar em seu lugar? E assim por diante.

Para mudar o tipo de imersão, buscamos compreender um estilo de jogo cuja base é a narrativa: o Role Playing Game (RPG). Fazendo assim, teremos os recursos mais convenientes para desenvolver o projeto de um novo jogo.

\section{A NARRATIVA PARTICIPATIVA E SEU PERSONAGEM}

Se não fosse a narrativa, o RPG não existiria. De acordo com Edson Ribeiro Cupertino (2008), a narrativa é o princípio do jogo, um jogo imaginário; afinal, trata-se de produzir ficção, e em grupo.

A premissa social do jogo é importante. Joris Dormans descreve como o grupo de jogadores se reúne, os verdadeiros rituais: "Eles fazem isso para jogar um jogo divertido, ouvir uma boa história, atuar como um personagem interessante ou simplesmente pela oportunidade de beber algumas cervejas com os amigos" (DORMANS, 2006).

Com isso, podemos afirmar que o jogo é jogado a partir de uma narrativa e ele se constrói em grupo, ou seja, a narrativa é compartilhada. Cupertino (2008) ressalta que, durante o jogo, devem ser respeitados suas regras e os conceitos que cercam a narrativa. 
Diferente de uma história pronta, o jogador assemelha-se a um ator improvisando suas ações de acordo com a resposta de seus companheiros. Essa atitude reforça a imersão que começa desde a preparação do jogo e se mantém até o fim. O fim, aliás, chega apenas quando a história termina (MURRAY, 2003).

Dormans (2006), comparando o xadrez ao RPG, coloca o primeiro como um jogo competitivo baseado quase estritamente em regras para definir apenas um vencedor e um perdedor. Já no segundo, as regras são determinadas pelos próprios jogadores de acordo com a narrativa, que pode ter um final depois de uma sessão ou durar por tempo indeterminado.

Cada jogador controla um ou mais personagens, e durante o jogo comporta-se como tal. Murray descreve a transição entre jogador e personagem como uma máscara. Ela é o que divide o mundo real do mundo ficcional, e, conforme uma pessoa interpreta, reforça o mundo imaginário e aumenta a imersão. A pessoa exerce "uma faculdade criativa" (MURRAY, 2003, p. 111).

Estabelecemos, assim, o personagem como essência do RPG. Cupertino cita que não há narrativa sem personagem, ou, do contrário, seriam apenas descrições vazias, sem ação. É este que "une narrativa e jogo, intermediado pela interpretação do jogador, cujo controle repercute na narrativa numa relação de causa e efeito" (CUPERTINO, 2008, p. 28).

Desse momento em diante, a transição da imersão estratégica para narrativa se dará, portanto, a partir do personagem. No xadrez, como ficou evidente, não há valorização das peças como personagens, pois elas representam muito mais a sua regra de movimentação do que propriamente sua forma.

Não há o in character e o out of character. O jogador é ele mesmo durante toda a partida, que pode transcorrer em completo silêncio até o xeque-mate.

O primeiro passo do projeto do novo jogo, portanto, é acrescentar um novo personagem ao xadrez, um herói, que traga com ele uma narrativa de base sobre a qual o jogador possa criar sua participação.

\section{O HERÓI - O ESTANDARTE DA NARRATIVA}

O herói como personagem não é uma escolha arbitrária. Quando Cupertino (2008, p. 40) diz que o RPG "evoca o critério inerente ao perfil psicológico do herói", refere-se ao mesmo que Murray (2003) quando cita o trabalho de Joseph Campbell sobre o "monomito", uma fórmula que se repete em diversas narrativas. Resumidamente, o personagem sai de um lugar comum, enfrenta desafios e provações e retorna transformado, vitorioso. Significa dizer que a narrativa do herói possui elementos primitivos da linguagem que, ao serem rearranjados, produzem histórias diferentes, mas igualmente sedutoras.

Esse método quase matemático de criar narrativas é fundamental para a narrativa interativa ou participativa. Se os jogadores de RPG não tivessem parâmetros para a criação da história, seria trabalhoso não só construí-la, como também definir as regras e o papel de cada um no jogo.

A inserção de uma nova peça no tabuleiro tradicional com 64 subdivisões, no entanto, rompe com a simetria formal do jogo. Como a intenção é mantê-la, optamos por usar a variação hexagonal do xadrez conhecida por variação de Gliński, de acordo com Pritchard (1994), em sua obra The classified encyclopedia of chess variants. 
Dessa variação usamos a forma do tabuleiro e a movimentação das peças com exceção do peão, que deve ser adaptado (Figura 1); já o número de peças e a disposição mantivemos similar ao tradicional (Figura 2). Assim, a nova peça fica entre os peões, à frente do exército, mantendo a simetria desejada.
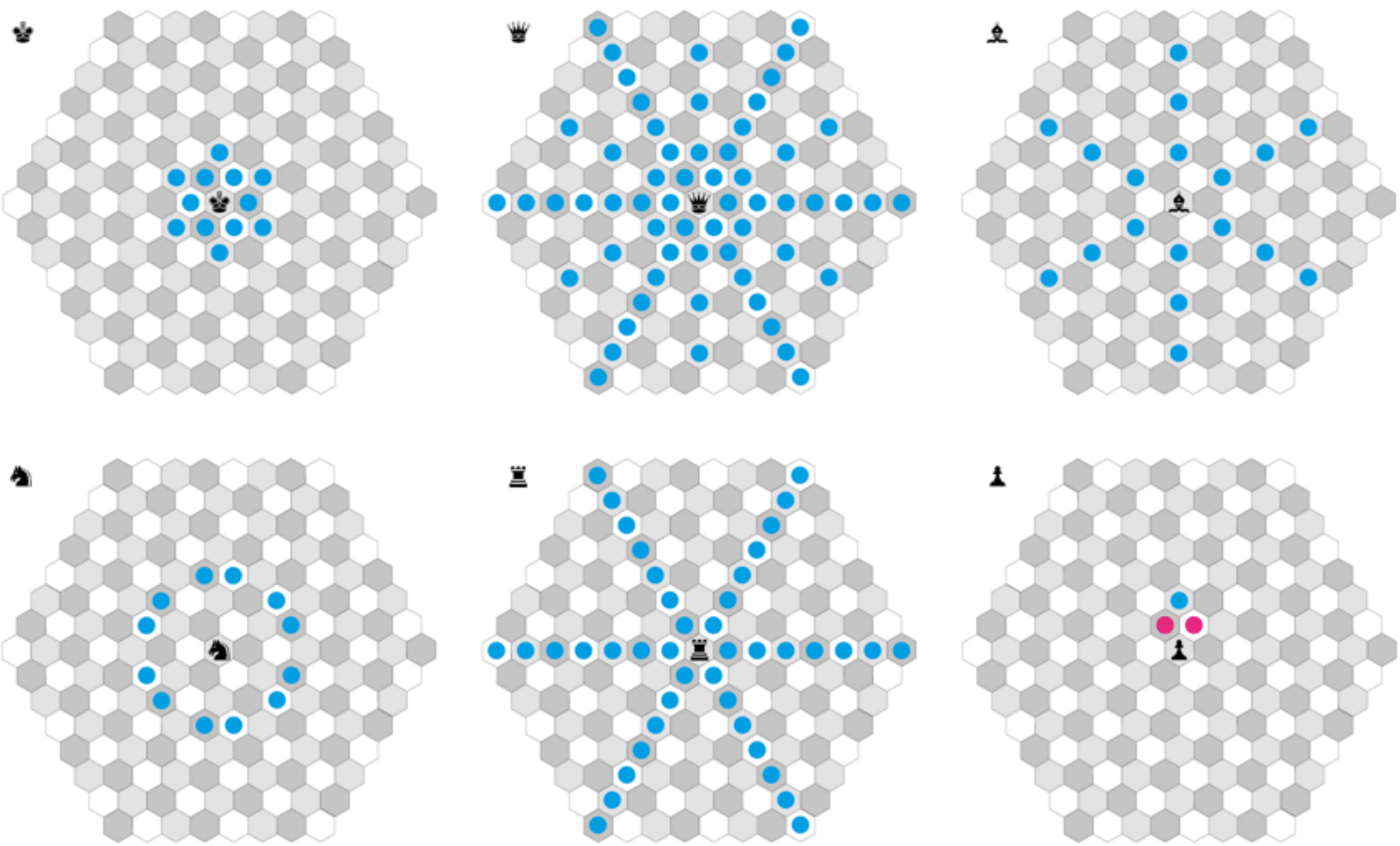

Figura 1 - Movimentação das peças.

Fonte: elaborado pelo autor, com base na pesquisa realizada

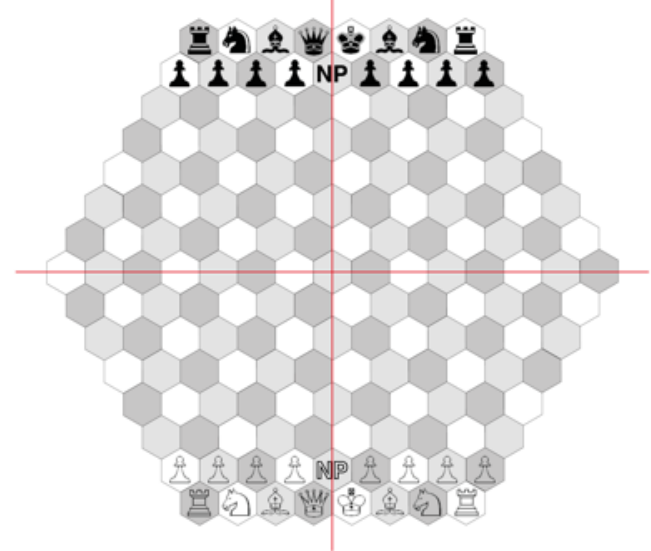

Figura 2 - Disposição inicial das peças no tabuleiro

Fonte: elaborado pelo autor, com base na pesquisa realizada

A forma hexagonal do tabuleiro permite que joguem até três jogadores ao mesmo tempo, e, juntando um ao outro, temos a possibilidade de vários participantes, agregando dessa forma o aspecto social do RPG no que se refere ao grupo de amigos. Um número grande de jogadores torna possível a criação de aventuras bem elaboradas, com alianças, troca de favores, traições etc. (Figura 3). 


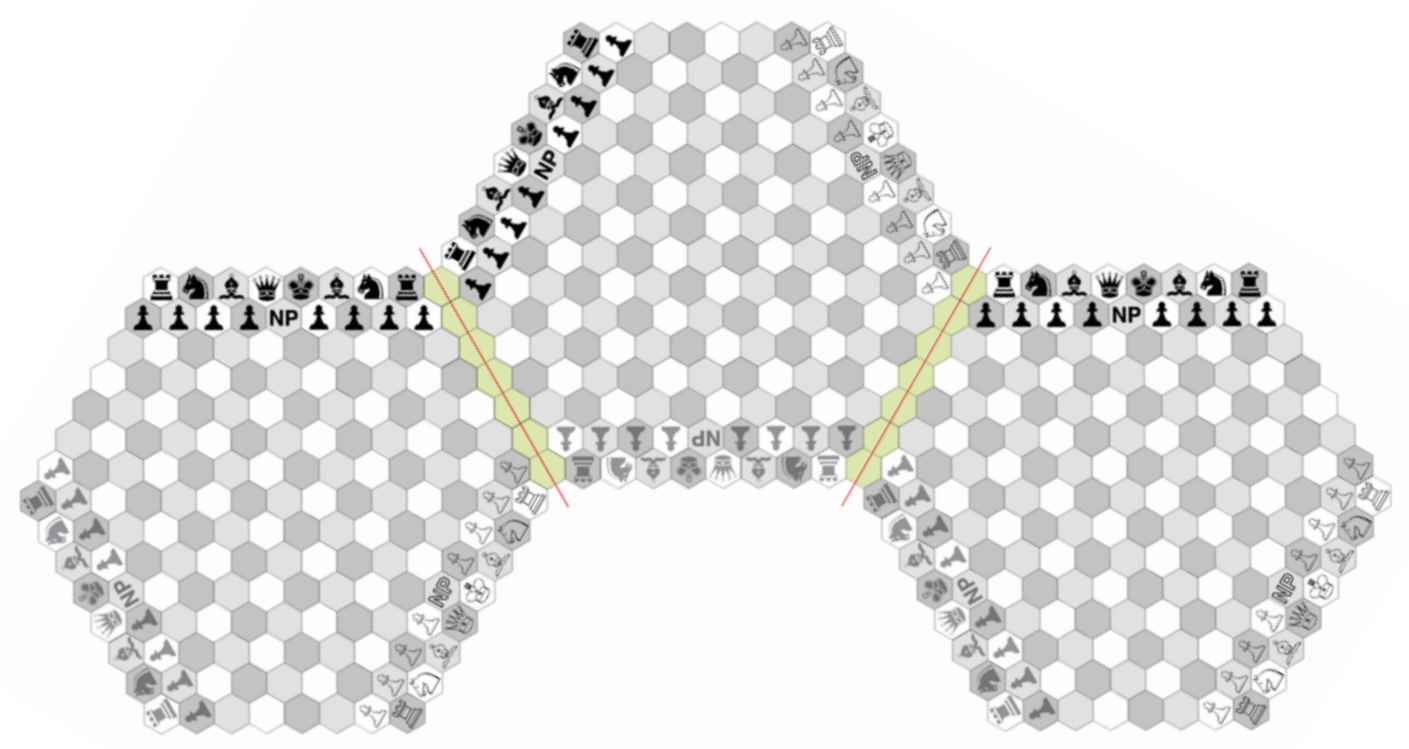

Figura 3 - Tabuleiros unidos para mais de três jogadores simultâneos

Fonte: elaborado pelo autor, com base na pesquisa realizada

Cada participante começa a ter um papel bem definido dentro da narrativa criada pelo grupo, e, como cita Murray, em referência aos LARPs: "Os papéis bem definidos fornecem os meios para que cada participante individual construa ativamente sua crença no mundo ilusório, e para que todos eles formem um poderoso círculo de encantamento" (MURRAY, 2003, p. 119).

LARPs, de acordo com a autora, são "jogos de representação com ação ao vivo" (p. 117) e, para que funcionem, são necessárias formas claras de participação. As peças do xadrez identificam-se como mecanismos de participação, entretanto, não estimulam necessariamente uma representação do ponto de vista da narrativa.

Murray (2003) e Cupertino (2008) referem-se às fichas de personagens no RPG como uma ferramenta poderosa de estimulo à representação. Esses perfis fornecem uma base fértil de informações sobre as quais são construídos os papéis de cada participante dentro da narrativa. Esta, por sua vez, é orientada pelo mestre, que organiza o jogo e controla todas as adversidades que sobrevêm aos jogadores.

Há casos, no entanto, em que não existe a figura do mestre, e o próprio jogo é quem determina algumas bases e conduz a criação das fichas dos personagens. Fiasco, por exemplo, de Jason Morningstar, é um RPG que dispensa o mestre e é voltado quase que exclusivamente à narrativa participativa. Este jogo é mostrado num vídeo digital disponível na internet por Wil Wheaton e mais três convidados.

Semelhantemente ao que é mostrado por Wil no vídeo, é conveniente o desenvolvimento de um material impresso com uma base para criação narrativa, sugestões. Exemplo: Europa, século XIV, durante os crescentes conflitos que deram origem à Guerra dos Cem Anos. Este pequeno fragmento já permite pensar nos personagens. O herói será um nobre? Um camponês? Um mercenário contratado?

Para auxiliar a responder a estas perguntas, após a sugestão de base viriam duas fichas: necessidade e local. Se uma das necessidades fosse "Resgate", e uma das sugestões de resgate fosse "... de um objeto mágico em posse de um membro da 
Igreja", os próprios jogadores poderiam discutir qual objeto mágico seria e o que ele seria capaz de fazer.

O uso de dois dados comuns, de seis lados, resolve esta primeira etapa. Cada jogador deverá rolar os dados na sua vez e definir, de acordo com o resultado, as necessidades e o local.

A necessidade estará diretamente relacionada ao herói. E como o herói é a máscara do jogador, esta sugestão definirá as condições para o fim da partida. Sendo assim, quando o jogador escolhe, de acordo com o resultado de seus dados, que sua necessidade é "Resgate... de um objeto mágico em posse de um membro da Igreja", seu foco estará voltado para a captura dos dois bispos adversários. A captura do rei e da rainha continuará, independentemente da necessidade, sendo o fim da partida - e, por isso, quando o inimigo estivesse prestes a capturar o rei ou a rainha, o herói poderia trocar os bispos por eles, de forma que a necessidade do herói inimigo estaria atendida e o jogo chegaria ao fim. Entretanto, o herói poderia recusar-se a entregar os bispos pelos reis e propor uma segunda batalha/partida.

Nesta segunda partida, a necessidade de um herói continua sendo a captura dos bispos, mas a necessidade do outro passaria a ser o resgate do rei prisioneiro em campo inimigo. Dessa maneira, temos uma dinâmica flexível e que coloca o objetivo da partida e o número de vezes que se joga a favor da narrativa.

Mas, para evitar que os jogadores - ainda que tenham criado personagens interessantes - voltem a pensar nas estratégias durante o jogo, o herói será influenciado tanto pelo jogador como por eventos.

\subsection{As cartas de evento}

Eventos serão cartas com pedaços de narrativa. Murray (2003) descreve o processo de criação de histórias dos bardos de forma muito semelhante ao que propomos. Memorizavam frases simples e substituíam, completavam e reorganizavam com novas palavras para produzir resultados diversos.

Relacionadas apenas ao personagem herói, funcionarão como o mestre do RPG, comunicando aos jogadores um trecho da história e deixando-os livres para tomar a próxima decisão. Cada jogador deve ter seu próprio conjunto de cartas, e começa o jogo com apenas uma carta em mãos. Por turno, ele deve revelar ou não uma carta ao adversário, e descartar uma. Ele deve escolher se comunica ao outro um ou mais eventos antes de movimentar seu personagem, ou qualquer outra peça.

Em algum momento o jogador poderá revelar de seu conjunto uma carta que diga: "Dispararei uma flecha envenenada poderosa para atingir e capturar ao menos três soldados inimigos adjacentes. É uma pena que minha flecha não tenha efeito em torres, cavalos ou reis e belas rainhas, mas há que se tentar!". Se o herói do jogador estiver a três espaços do bispo do jogador oponente, ele pode anunciar esse evento antes da jogada e, então, capturar a peça que precisa.

O trecho acima poderia ser escrito desta forma: "Flecha envenenada: alcance de 3 casas adjacentes. Não tem efeito em torres, cavalos, rei e rainha". Este tipo de escrita é mais objetiva, clara e concisa, entretanto, apresenta informações neutras do ponto de vista da narrativa.

Se a intenção é romper com a imersão estratégica do xadrez, esse tipo de redação não é conveniente por revelar apenas dados estratégicos. Katie Salen e Eric Zimmerman (2004, p. 28) ressaltam: "Como algo é dito é tão importante quanto o que 
é dito quando você está criando contextos narrativos". Assim, com o texto na primeira pessoa, sem revelar gênero, basta o jogador lê-lo para seu adversário que já estará se colocando na posição de seu personagem.

As informações estratégicas, mais objetivas, podem vir num guia do jogo, como um dicionário, impresso ou disponível na internet. Se nas cartas consta o termo "dia", no guia constaria a tradução: turno.

Os eventos tornam importante, também, a escolha da sugestão "Local" na etapa de preparação do personagem. Propusemos a existência de cartas nas quais o evento diga: "Porei fogo neste terreno e trarei o caos! Quero ver se ao cabo de cinco dias pelo menos cinco soldados da infantaria inimiga não estarão capturados!". Se a batalha for num terreno alagado, este evento não poderá ser usado. O jogador pode simplesmente descartá-lo. Outras cartas poderiam conceder algum tipo de vantagem, dependendo do terreno, e assim por diante.

Outro aspecto importante relaciona-se à quantidade de cartas com que o jogador começa o jogo em mãos e ao nível de seu personagem. Foi dito que o jogador iniciaria o jogo com apenas uma carta, o que significa que ele é de nível 1 . Se ele vencer a primeira batalha e a guerra continuar, ele inicia a próxima partida com duas cartas, pois estará no nível 2. O recurso de nível também é característico dos jogos de RPG. Cupertino (2008) explica que no RPG o herói desenvolve-se na narrativa, e isso se reflete na mecânica do jogo por meio de pontuações que vão servir para melhorar, por sua vez, seu desempenho na narrativa.

É justo que o herói vencedor tenha uma recompensa por seu sucesso. Deste modo, se o jogador disser que é um herói de nível 10, significará que, ao jogar, ele iniciará a partida com dez cartas de evento em mãos.

Para equilibrar o jogo, eventos muito importantes - como recuperar uma peça ou acrescentar uma peça ao exército - devem ter um custo de igual importância. Supondo que em uma carta conste que o herói invocará a alma da rainha para o jogo por cinco dias. Então, para fazer a invocação, ele deverá sacrificar um bispo e uma torre. Entretanto, esse sacrifício pode ou não ser permanente.

A resposta para isso estaria na diferença entre as personalidades dos heróis. A distinção poderá estar na forma das peças, claro, mas estará principalmente nas cartas de evento e no custo delas. Cada conjunto de cartas terá uma personalidade e o jogador poderá escolher aquele que lhe for mais conveniente: o conjunto com uma redação mais educada, pautada por valores como honra, fé e altruísmo, ou o conjunto com uma redação desdenhosa, pautada pela trapaça, ceticismo e egoísmo.

No primeiro caso, a volta da rainha seria por cinco dias/turnos; depois destes, a rainha voltaria ao seu repouso, e tanto o bispo quanto a torre retornariam à batalha, pois é justo. No segundo caso, a rainha poderia voltar permanentemente sacrificando o bispo e a torre até o fim da partida, o que soa mais egoísta.

Além disso, tais personalidades definiriam pelo menos três movimentações diferentes para o herói: igual à torre, igual ao cavalo ou igual ao bispo. Entretanto, novamente para manter o equilíbrio, a movimentação semelhante à torre e ao bispo é limitada pelo número de hexágonos igual à do cavalo: três. Assim, todos terão a mesma vantagem. 


\section{CONCLUSÃO}

O xadrez parece ter sido criado a partir de uma narrativa. Não parece que um conjunto de regras foi inventado primeiro, para depois ser aplicada sua estética de batalha, mas ele nasceu da batalha, inspirado por ela e para representá-la, recriá-la. Com o tempo, essa estética narrativa se descolou e restaram apenas representações formais das peças, padronizadas por uma questão de campeonatos e clubes, como pudemos observar.

O jogo é silencioso, as vezes solitário, e profundamente estratégico. E lá permanecem as torres, os cavalos, os bispos, a rainha, o rei e os peões, como meras nomenclaturas. Decidimos mudar, e discutimos as ferramentas convenientes para personificar essas nomenclaturas, conferir a cada uma delas seu valor narrativo.

O projeto buscou no RPG a máscara, e colocou no xadrez o herói. 0 personagem principal, o jogador, com uma necessidade clara, diferente, e guiado por uma série de eventos sorteados do conjunto de cartas embaralhado, rompe de vez com a imersão estratégica.

Isso evidencia que, para uma narrativa fazer sentido em um jogo, ela deve necessariamente estar entrelaçada com a mecânica. Se uma mudança da narrativa não interferir em como o jogador pode mover seu personagem, ela pode ser descartada. Não basta ter uma história de base, se não houver estímulos para que os jogadores possam enriquecê-la. Do contrário, em pouco tempo as histórias são ignoradas, e, semelhantemente ao que aconteceu com o xadrez no decorrer de sua história, a mecânica estará completamente desnuda e será ela a seduzir o jogador.

$\mathrm{Na}$ teoria, como no RPG, serão criadas novas regras ou modificadas regras existentes de acordo com a narrativa quando se jogar a variação proposta pelo projeto. Esta variação do xadrez deixa de ter uma mecânica rígida e passa a ser fluida. Cada batalha pode terminar por uma necessidade satisfeita e, ao mesmo tempo, dar origem a outra batalha, fazendo uma guerra durar por uma tarde, ou por alguns anos.

$\mathrm{Na}$ prática, exigirá uma prototipação e testes, o que vai além do caráter projetual da pesquisa que expusemos, mas que certamente enriquecerá nossa discussão e trará novas - e interessantes - considerações.

\section{REFERÊNCIAS}

ADAMS, Ernest. Postmodernism and the three types of immersion. Gamasutra, 9 July 2004. Disponivel na internet por http em: <http://designersnotebook.com/Columns/063_Postmodernism/063_ postmodernism.htm>. Acesso em 26 maio 2013.

CUPERTINO, Edson Ribeiro. Vamos jogar RPG? Diálogos com a literatura, o leitor e a autoria. Dissertação (Mestrado em Letras) - Universidade de São Paulo, São Paulo, 2008.

DORMANS, Joris. On the role of the die: a brief ludologic study of pen-and-paper roleplaying games and their rules. Game Studies, v. 6, n. 1, Dec. 2006. Disponível na internet por http em: <http://gamestudies.org/0601/articles/dormans>. Acesso em 26 maio 2013. 
FORBES, Duncan. The history of chess: from the time of the early invention of the game in India till the period of its establishment in western and central europe. Cambridge: Harvard University, 1860.

HUNICKE, Robin; LEBLANC, Marc; ZUBEK, Robert. MDA: a formal approach to game design and game research. Disponível na internet por http em: <http://www.cs.northwestern.edu/ hunicke/MDA.pdf>. Acesso em 26 maio 2013.

MURRAY, Janet $\mathrm{H}$. Hamlet no Holodeck - $\mathrm{O}$ futuro da narrativa no ciberespaço. São Paulo: Unesp, 2003.

NIFTY 50 ! Kasparov wins in exactly $\mathbf{5 0}$ moves. The official website of Garry Kasparov, 13 Apr. 2013. Disponível na internet por http em: <http://www.kasparov.com/nifty50-kasparov-wins-in-exactly-50-moves/>. Acesso em 26 maio 2013.

PRITCHARD, David B. The classified encyclopedia of chess variants. Surrey, UK: Games and Puzzles Publications, 1994.

SALEN, Katie; ZIMMERMAN, Eric. Rules of play: game design fundamentals. Cambridge: Massachusetts Institute of Technology, 2004.

STRAMP, Jimmy. How the chess set got its look and feel. Smithsonian.com, 3 Apr. 2013. Disponível na internet por http em: <http://blogs.smithsonianmag.com/design/2013/04/how-the-chess-set-got-its-lookand-feel/>. Acesso em 26 maio 2013.

ZIMMERMAN, Eric. Narrative, interactivity, play and games: four naughty concepts in need of discipline. Eric Zimmerman, 2004. Disponível na internet por http em: <http://www.ericzimmerman.com/texts/Four_Concepts.html>. Acesso em 26 maio 2013. 